\title{
Rubus ulmifolius Schott fruits: A detailed study of its nutritional, chemical and bioactive properties
}

\author{
Liliana Primo da Silva, Eliana Pereira, Tânia C.S.P. Pires, Maria José Alves, Olívia R. Pereira, \\ Lillian Barros*, Isabel C.F.R. Ferreira* \\ Centro de Investigação de Montanha (CIMO), Instituto Politécnico de Bragança, Campus de Santa Apolónia, 5300-253 Bragança, Portugal
}

\section{A R T I C L E I N F O}

\section{Keywords:}

Rubus ulmifolius

Fruits

Nutritional and physical characterization

Chemical composition

Phenolic profile

Antimicrobial activity

\begin{abstract}
A B S T R A C T
There is a growing interest in wild edible species that represent a source of several health-promoting compounds, providing a potential strategy to diversify and enrich the daily diet. The aim of the present work was to characterize the nutritional and chemical composition of Rubus ulmifolius Schott fruits. Furthermore, their antimicrobial activity, non-anthocyanin and anthocyanin phenolic profile were also determined. According to the obtained results, $R$. ulmifolius fruits exhibited a high concentration in carbohydrates and a low fat content, in comparison with the other nutrients and non-nutrients detected in this sample. The colour parameters demonstrated differences in $a^{*}$ and $b^{*}$ parameters after lyophilisation process. Glucose and fructose were the most abundant free sugars detected and quinic acid showed the highest content compared to the other five organic acids identified. The fatty acids profile revealed 25 compounds, being mostly represented by polyunsaturated fatty acids and evidencing linolenic and $\alpha$-linolenic acid as the most abundant. All tocopherol isoforms were detected, revealing $\gamma$-tocopherol with highest amount. Cyanidin-3-O-glucoside, ellagic acid pentoside, ellagic acid glucuronide and sanguiin $\mathrm{H}-10$ were the main phenolic compounds present, which could be related to the antimicrobial activity (MIC values ranging between 5 and $20 \mathrm{mg} / \mathrm{mL}$ ) revealed by $R$. ulmifolius fruits. These results showed that this fruit is a good source of nutrients as also non-nutrient compounds, with human health benefits.
\end{abstract}

\section{Introduction}

In recent years, there has been an increasing concern from consumers regarding food safety and quality, which has resulted in the increasing demand for natural food products (Asioli et al., 2017; Moscato \& Machin, 2018). The preference for unprocessed foods (processed and industrialized products) is mostly due to its higher content in bioactive compounds, which involve several bioavailable compounds that have been associated with healthy benefits, unlike refined foods. During the industrialization process, refined foods loose a great amount of components, such as fibers, nutrients, vitamins and other molecules, and consequently present a higher content of simple carbohydrates, salt and fats, adding a higher energetic value to the product (Moubarac, Batal, Louzada, Martinez Steele, \& Monteiro, 2017; Rodríguez-Roque et al., 2015). In addition to the direct consequences in the nutritional value of the food product, consumers have also shown a great concern about the environmental impact caused by the abusive use of synthetic fertilizers and pesticides in the contamination of the soil and machinery as consequence of intensive industrialization (Sun, Dai, \& Yu, 2017).
Thus, actually, there is a growing interest in wild edible species that represent a source of several health-promoting compounds providing a potential strategy to diversify and enrich the daily diet and thus a contribution to combat global health disorders (Morales et al., 2013). Since wild species do not require specific conditions and action for their generation, it becomes an inexhaustible resource and therefore an added value for the food sector (Bacchetta et al., 2016; Emilia \& Accame, 2016; Pinela, Carvalho, \& Ferreira, 2017; Ruiz-Rodríguez et al., 2014).

Rubus ulmifolius Schott (Roseaceae) is a perennial shrub commonly known as wild blackberry or elm-leaf blackberry that is widely distributed in Asia, North Africa and Europe, predominantly in Iberian Peninsula, in both wild and cultivated soils (Emilia \& Accame, 2016; Martins et al., 2014; Reidel, Melai, Cioni, Flamini, \& Pistelli, 2016). The blooming season occurs between May and June, followed by the ripening and development of the fruit, that is characterized as an aggregate of several fleshy drupelets, that during ripening change their colour from green to black (Emilia \& Accame, 2016; Reidel et al., 2016). These fruits are consumed fresh or as derivate products such as

\footnotetext{
* Corresponding authors.

E-mail addresses: lillian@ipb.pt (L. Barros), iferreira@ipb.pt (I.C.F.R. Ferreira).
} 
jams, juices, liqueur and marmalades, due to their delicious flavour and taste. Furthermore, their bioactive compounds have been the main focus of many scientific studies, generating a large number of dietary supplements and food products fortified with phytochemicals (D'Agostino et al., 2015; Emilia \& Accame, 2016; Reidel et al., 2016). Their therapeutic properties are assigned to the high concentration of biologically active compounds such as phenolic compounds, ellagitannins and ascorbic acid (Barros, Oliveira, Carvalho, \& Ferreira, 2010; Oszmiański et al., 2015). Thus, an interdisciplinary approach should be applied for the valorization of wild species, deliberating and encourage about new projects linked to an ecologically sustainable extraction of bioactive compounds, and therefore to future applications in industry (Emilia \& Accame, 2016; Ruiz-Rodríguez et al., 2014). Several studies have been performed using different Rubus species, such as Rubus ideaus, Rubus takesimensis and Rubus suavissimis (Milivojevic et al., 2011; Uhler \& Yang, 2018; Yang, Pak, \& Kim, 2018). Deeper studies were carried out in blackberry (Van de Velde, Pirovani, \& Drago, 2018), in Rubus ulmifolium flowers buds and open flowers (Barros et al., 2010), and in Rubus ulmifolium fruits (Ruiz-Rodríguez et al., 2014). The present study evidences novelty in the chemical and bioactive characterization of $R$. ulmifolium fruits, and deepens the evaluation of compounds with bioactive interest, such as polyphenols. Thus, it was performed a nutritional and chemical evaluation of $R$. ulmifolius fruits, as well as, a discrimination of its phenolic compounds profile (non-anthocyanin and anthocyanin compounds) and antimicrobial activity.

\section{Materials and methods}

\subsection{Samples}

Rubus ulmifolius Schott fruits (Rosaceae) known as elm-leaf blackberry or wild blackberry were collected during September 2017 in Bragança, Portugal. The collected plant material was authenticated by Professor of Botany Carlos Aguiar and a specimen voucher was deposited in the herbarium of the School of Agriculture, Polytechnic Institute of Bragança (Portugal).

The fruits (200 g) were lyophilized (FreeZone 4.5, Labconco, Kansas City, MO, USA), reduced to a fine dried power ( $\sim 20 \mathrm{mesh})$ and then mixed to obtain a homogenous mixture. The samples were stored in a fresh and dry place, away from any light source until further analysis.

\subsection{Nutritional characterization of R. ulmifolius fruits}

The protein, fat, carbohydrates and ash content were obtained according AOAC (2016) procedures and using methodologies described by Melgar et al. (2017). For the crude protein $(\mathrm{N} \times 6.25)$ was used Kjeldahl method (AOAC 991.02), the ash content was obtained by exposing the sample to incineration at $550 \pm 15^{\circ} \mathrm{C}$ for $12 \mathrm{~h}$ (AOAC 935.42), whereas the crude fat was obtained by using a Soxhlet apparatus with petroleum ether as recycling solvent (AOAC 989.05) and, finally, the total carbohydrate was assessed through difference. To determine the total energy, it was used the following equation: Energy $(\mathrm{kcal})=4 \times(\mathrm{g}$ protein $+\mathrm{g}$ carbohydrates $)+9 \times(\mathrm{g}$ fat $)$.

\subsection{Colour parameters analysis of $R$. ulmifolius fruits}

This evaluation was performed according a procedure described by Roriz, Barros, Prieto, Morales, and Ferreira (2017). To measure the samples colour it was used a Minolta spectrophotometer (Konica Minolta Sensing, Inc., Chroma Meter CR-400, Japan) with an adapter for granular materials (model CRA50). Using the illuminant $\mathrm{C}$ and a diaphragm aperture of $8 \mathrm{~mm}$, the CIE $L *, a *$ e $b *$ colour space values were reported through the computerized system, using colour data software Spectra Magic Nx (version CM-S100 W 2.03.0006, Konica Minolta Company, Japan) to process the data.

\subsection{Nutrients composition of $R$. ulmifolius fruits}

Free sugars were analysed, using the high performance liquid chromatography - HPLC (Knauer, Smartline system 1000) coupled to a refraction index detector - RI (Knauer, Smartline system 1000), as previously described by Barros et al. (2013). The results were evaluated using a Clarity 2.4 Software (DataApex, Podohradska, Czech Republic), through which expressed in $\mathrm{g}$ per $100 \mathrm{~g}$ of fresh weight (fw). The standards $(\mathrm{D}(-)$-fructose, $\mathrm{D}(+)$-sucrose, $\mathrm{D}(+)$-glucose, $\mathrm{D}(+)$-trehalose and $\mathrm{D}(+)$-raffinose pentahydrate) and all other general laboratory reagents were purchased from Sigma-Aldrich (St. Louis, MO, USA) and Panreac Química S.L.U. (Barcelona, Spain), respectively.

Organic acids were evaluated through an ultra-fast liquid chromatography (UFLC, Shimadzu 20A series, Kyoto, Japan) coupled to a photodiode array detector (PDA), according to a technique previously explained by Barros, Pereira, and Ferreira (2013). The results were evaluated using a LabSolutions Software (Software) and expressed in $g$ per $100 \mathrm{~g}$ of fresh weight (fw). Organic acids standards, such as: $\mathrm{L}$ (+)-ascorbic acid, citric acid, malic acid, oxalic acid, shikinic acid, succinic acid, fumaric acid, and quinic acid, were obtained from SigmaAldrich (St. Louis, MO, USA).

Fatty acids procedure was performed according to a methodology reported by Pereira, Barros, Martins, and Ferreira (2012), using a gas chromatography (DANI model GC 1000, Contone, Switzerland) coupled to a flame ionization detector (FID), a split/splitless injector and a Zebron-Kame column $\left(30 \mathrm{~m} \times 0.25 \mathrm{~mm}\right.$ ID $\times 0.20 \mu \mathrm{m} \mathrm{d}_{\mathrm{f}}$; Phenomenex, Lisbon, Portugal). The compounds were identified by comparison of the relative retention times of FAME peaks from samples with commercial standards (standard 47,885-U was purchased from Sigma-Aldrich, St. Louis, MO, USA). The results were treated using a chromatography station for Windows CSW (version 1.7) software from DataApex (Podohradska, Czech Republic) and exhibited in relative percentages (\%).

Tocopherols content was obtained following a method previously described by Barros, Pereira, Calhelha, et al. (2013), using a HPLC system (Knauer, Smartline system 1000) coupled to a fluorescence detector (FP-2020; Jasco; Easton, MD, USA) and programmed for excitation at $290 \mathrm{~nm}$ and emission at $330 \mathrm{~nm}$. The results were evaluated using a Clarity 2.4 Software (DataApex, Podohradska, Czech Republic), through which expressed in $\mathrm{mg}$ per $100 \mathrm{~g}$ of fresh weight (fw). Tocopherols commercial standards ( $\alpha$-, $\beta-, \gamma$-, and $\delta$-tocopherol) were obtained from Matreya (Pleasant Gap, PA, USA).

\subsection{Phenolic composition of R. ulmifolius fruits}

\subsubsection{Non-anthocyanin compounds}

Extraction and purification. The fruit sample was extracted by macerating $1 \mathrm{~g}$ with ethanol/water $(30 \mathrm{~mL}, 80: 20, v / \mathrm{v})$ during $1 \mathrm{~h}\left(25^{\circ} \mathrm{C}\right.$, $250 \mathrm{~g}$ ). Afterwards, the sample was filtered and the remaining residue was extracted with an additional portion of the hydroethanolic mixture during $1 \mathrm{~h}$. The filtrated extract was concentrated under reduce pressure (rotary evaporator Büchi R-210, Flawil, Switzerland) at $35^{\circ} \mathrm{C}$, until complete ethanol removal. The aqueous phase was then frozen and lyophilized $\left(-47^{\circ} \mathrm{C}, 0.045\right.$ bar; FreeZone 4.5 , Labconco, Kansas City, MO, USA).

The aqueous phase was purified using a C-18 SepPak ${ }^{\circledast}$ Vac $3 \mathrm{~cm}^{3}$ cartridge (Phenomenex). The activation was performed with $5 \mathrm{~mL}$ of ethanol and water, then $10 \mathrm{~mL}$ of the sample $(50 \mathrm{mg} / \mathrm{mL})$ was loaded into the cartridge. Afterword's, the sugars and the more polar compounds were removed by passing $15 \mathrm{~mL}$ of water and the phenolic compounds were further eluted with $15 \mathrm{~mL}$ of ethanol. Afterwards, the ethanol was removed under vacuum until dryness and re-dissolved in $1 \mathrm{~mL}$ of $80 \%$ aqueous ethanol, filtered through a $0.22 \mu \mathrm{m}$ disposable LC filter disk into a $1.5 \mathrm{~mL}$ amber vial for HPLC analysis (Rodrigues et al., 2012).

Analytical method. The analysis was performed using a chromatographic system Dionex Ultimate 3000 UPLC (Thermo Scientific, San 
Jose, CA, USA). Detections was performed simultaneously with a DAD $(280,330$, and $370 \mathrm{~nm})$ and with a mass spectrometer (Linear Ion Trap LTQ XL, Thermo Finnigan, San Jose, CA, USA) equipped with an ESI source and operating in negative mode, following a procedure previously performed by the authors (Bessada, Barreira, Barros, Ferreira, \& Oliveira, 2016). The compounds were detected using the retention times, UV-VIS and mass spectra data in comparison with available standards and literature review. While quantitative analysis was performed using calibration curves of available phenolic standards (caffeic acid, $\mathrm{y}=388,345 \times+406,369$; ellagic acid, $\mathrm{y}=26,719 \times-317,255$; quercetin-3-O-glucoside, $\quad \mathrm{y}=34,843 \times \quad-\quad 160,173$; taxifolin, $y=203,766 \times-208,383$ ) based on the UV signal. In the case of unavailable commercial standards, the compounds were quantified based on the calibration curve of the most similar standard available. The results were exhibited as in $\mathrm{mg}$ per $\mathrm{g}$ of extract.

\subsubsection{Anthocyanin compounds}

Extraction. Each sample $(1 \mathrm{~g})$ was extracted through a maceration extraction methodology during $1 \mathrm{~h}$, with $30 \mathrm{~mL}$ of ethanol/water $(80: 20, v / v)$ containing $0.5 \% \mathrm{HCl}$. After filtration (Whatman No. 4 paper), the residue was re-extracted with $30 \mathrm{~mL}$ of ethanol/water $(80: 20, v / v)$ acidified with $0.5 \% \mathrm{HCl}$. In order to remove ethanol, the combined extracts were evaporated at $35^{\circ} \mathrm{C}$, under reduced pressure and further lyophilized. Extracts were re-dissolved in $1 \mathrm{~mL}$ of $80 \%$ aqueous ethanol acidified with $0.01 \%$ of $\mathrm{HCl}$, and filtered through a $0.22 \mu \mathrm{m}$ disposable LC filter disk into an amber vial for HPLC analysis.

Analytical method. This evaluation was made following a methodology described by Gonçalves et al. (2017), using a UPLC-DAD-ESI/ MSn system (Thermo Finnigan, San Jose, CA, USA). Detection was performed using a DAD $(520 \mathrm{~nm})$ and with a mass spectrometer (Linear Ion Trap LTQ XL Thermo Finnigan) equipped with an ESI source and operating in positive mode. Compounds identification was performed using the retention time, UV-VIS and mass spectra data in comparison with available standards (cyanidin-3-O-glucoside, $y=104,478 \times-$ 823,429 and pelargonidin-3-O-glucoside, $y=50,652 \times-696,848$ ) and literature review. The results were expressed in $\mathrm{mg} / \mathrm{g}$ of extract.

\subsection{Antimicrobial activity R. ulmifolius fruits}

To evaluate the antimicrobial activity, the hydroethanolic extract described in Section 2.5.1. were re-dissolved in water to obtain a stock solution of $100 \mathrm{mg} / \mathrm{mL}$ and, subsequently, submitted to further dilutions. The microorganisms used during this study were donated clinical isolates from patients hospitalized in various departments of the Local Health Unit of Bragança and Hospital Center of Trás-os-Montes and Alto-Douro, Vila Real, Portugal. Thus, five Gram-negative bacteria (Escherichia coli, Klebsiella pneumoniae, Morganella morganii, Pseudomonas aeruginosa and Proteus mirabilis), four Gram-positive bacteria (MRSA- methicillin-resistant Staphylococcus aureus, MSSA- methicillinsusceptible Staphylococcus aureus, Listeria monocytogenes and Enterococcus faecalis), and one fungi (Candida albicans) were used to access the antimicrobial activity.

Minimum inhibitory concentrations (MIC) were obtained by the microdilution method and the rapid $p$-iodonitrotetrazolium chloride
(INT, Panreac Applichem (Barcelona, Spain) colorimetric assay, following the methodology described by Alves, Ferreira, Martins, and Pintado (2012). MICs were defined as the lowest concentration that inhibits the visible bacterial growth and the results are present in $\mathrm{mg} /$ $\mathrm{mL}$. Minimal bactericidal and fungicidal concentration (MBC and MFC) were also determined, by measuring the lowest concentration that yielded no growth, therefore MBC and MFC were defined as the lowest concentration required to kill a bacteria and fungus. Ampicillin $(20 \mathrm{mg} /$ $\mathrm{mL}$ ), imipenem (1 mg/mL), vancomycin $(1 \mathrm{mg} / \mathrm{mL})$, and fluconazole (1 $\mathrm{mg} / \mathrm{mL}$ ) were used as positive control.

\subsection{Hepatotoxicity evaluation R. ulmifolius fruits}

The hepatotoxicity of the hydroethanolic extract described in Section 2.5.1 was evaluated in a non-tumor primary cell culture, obtained from a freshly harvested porcine liver, acquired from a local slaughterhouse, being designated as PLP2. This evaluation was performed according to a procedure described by Barros, Pereira, Calhelha, et al. (2013) and ellipticine (from Sigma-Aldrich, Sigma-Aldrich, St. Louis, MO, USA) was used as positive control. The results were exhibited in $\mathrm{GI}_{50}$ values, sample concentration that inhibits the growth of cells by $50 \%$.

\subsection{Statistical analysis}

The described assays were performed in triplicate and the results were expressed as mean \pm standard deviation (SD). The statistical treatment was analysed through the Student's $t$-test in order to determine the significant differences between two samples, with $p=0.05$ (SPSS v. 23.0; IBM Corp., Armonk, New York, USA).

\section{Results and discussion}

\subsection{Nutritional value and colour evaluation of $R$. ulmifolius fruits}

The nutritional analysis of $R$. ulmifolius fruits was performed and the results are provided in Table 1 . The nutritional evaluation was made through the analysis of proteins, fat, ash, carbohydrates and energy. $R$. ulmifolius fruits revealed a higher concentration of carbohydrates, with values of $26.2 \pm 0.2 \mathrm{~g} / 100 \mathrm{~g} \mathrm{fw}$, and low values of proteins $(2.4 \pm 0.1 \mathrm{~g} / 100 \mathrm{~g} \mathrm{fw})$, followed by fat $(1.22 \pm 0.02 \mathrm{~g} / 100 \mathrm{~g} \mathrm{fw})$ and ash $(0.58 \pm 0.01 \mathrm{~g} / 100 \mathrm{~g} \mathrm{fw})$. In the present work it was also evident the high level of moisture present in the fruits, with value of $70 \pm 2 \mathrm{~g} /$ $100 \mathrm{~g} \mathrm{fw}$. In an overall, the energetic value of fruits was $125.25 \pm 0.08 \mathrm{kcal} / 100 \mathrm{~g} \mathrm{fw}$.

Several studies have been carried out in other species of blackberries and the results show some differences in most of the studied parameters. De Souza et al. (2014) studied several red fruits, such as blackberry, red raspberry, strawberry, sweet cherry and blueberry, and the results showed different values in comparison with the present study, thus the highest and lowest concentrations were also found for the same parameters. These authors also presented different values for blackberry sample (Rubus spp), showing higher contents in carbohydrates, with values of $10.18 \mathrm{~g} / 100 \mathrm{~g} \mathrm{fw}$, followed by proteins with

Table 1

Nutritional parameters and physical parameter (colour - CIE $L^{*} a^{*} b^{*}$ ) of R. ulmifolius fruits.

\begin{tabular}{|c|c|c|c|c|c|}
\hline Nutritional value & Lyophilized fruit powder & Colour & Fresh fruit & Lyophilized fruit powder & p-value \\
\hline Moisture (g/100 g fw) & $69.63 \pm 1.9$ & $L^{*}$ & $19.7 \pm 0.2$ & $18.8 \pm 0.8$ & 0.006 \\
\hline Ash $(g / 100 g$ fw $)$ & $0.58 \pm 0.01$ & & & & \\
\hline Proteins $(\mathrm{g} / 100 \mathrm{~g} \mathrm{fw})$ & $2.4 \pm 0.1$ & $a^{*}$ & $1.19 \pm 0.05$ & $8.0 \pm 0.3$ & $<0.001$ \\
\hline Fat $(g / 100 \mathrm{~g} \mathrm{fw})$ & $1.22 \pm 0.02$ & & & & \\
\hline Carbohydrates $(\mathrm{g} / 100 \mathrm{~g} \mathrm{fw})$ & $26.17 \pm 0.17$ & $b^{*}$ & $1.21 \pm 0.05$ & $2.7 \pm 0.1$ & $<0.001$ \\
\hline Energy (Kcal/100 g fw) & $125.25 \pm 0.08$ & & & & \\
\hline
\end{tabular}

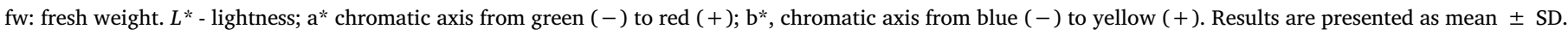


values of $1.27 \mathrm{~g} / 100 \mathrm{~g} \mathrm{fw}$; however, this last parameter presented a lower concentration compared to our result. The lowest concentrations were detected in fat and ash, presenting values of $0.42 \mathrm{~g} / 100 \mathrm{~g}$ fw and $0.21 \mathrm{~g} / 100 \mathrm{~g} \mathrm{fw}$, respectively. Also in these parameters it was verified lower values in comparison with the present study. Otherwise, the samples showed significantly higher moisture content, with values of $87.92 \mathrm{~g} / 100 \mathrm{~g} \mathrm{fw}$, and the opposite was observed in the energy content $(49.57 \mathrm{kcal} / 100 \mathrm{~g} \mathrm{fw})$, which was considerably lower compared to the present study. The differences observed with respect to the nutritional composition can be explained by the different provenance of the samples, but also because they correspond to different species (Pellegrini et al., 2018).

The values of three-dimensional coordinates CIE ( $L^{*}, a^{*}$ and $\left.b^{*}\right)$ for the colour analysis of the R. ulmifolius fruit samples are described in Table 1 . Colour is a very important parameter in the food industry since the visual aspect of a product will always have a first impact on the consumer and is often the decisive factor for the acceptance or not of the product. The fruits of blackberry have a very intense colour that remains and characterizes all derivative products such as marmalade, jam, liqueurs, ice cream and others (Kaume, Howard, \& Devareddy, 2012). $L^{*}$ is the coordinate that represents lightness, ranges from white (100) to black (0), and showed a value of 19.7 in fresh fruit; while $a^{*}$ represents the chromatic axis from green $(-)$ to red $(+)$ showing a value of 1.19 , and $b^{*}$ which represents the chromatic axis from blue $(-)$ to yellow $(+)$, showing a value of 1.21 for fresh fruits. On the other hand, the colour was also measured in fruits after being lyophilized and reduced to powder, and the results present values of 18.8, 8.0 and 2.7 for $L^{*}, a^{*}$ and $b^{*}$ parameters. According to these results and with the application of statistical analysis, it is evident that the differences between $a^{*}$ and $b^{*}$ parameters in the different samples, revealed that the lyophilisation process caused statistically significant differences for all colour parameters $(p<0.05)$. Thus, the $L^{*}$ parameter showed a decrease after the dehydration by lyophilisation (keeping the dark colour characteristic of this fruit), on the other hand, the $a^{*}$ and $b^{*}$ values evidenced an accentuated increase.

The present study cannot be compared with previous studies, since these analyses were not previously performed by other authors. Lyophilisation is a process that allows to obtain a high quality product; in this way it is important to evaluate its effects, in this case, with regard to colour change, allowing a small screening of the stained pigments, such as anthocyanin compounds, in this case.

\subsection{Chemical characterization of $R$. ulmifolius fruits in terms of nutrients}

The composition of the fruits was obtained evaluating the fatty acids, free sugars, organic acids, and tocopherols content and the results are presents in Table 2.

The analysis of free sugars revealed the presence of two monosaccharides (fructose and glucose) and one disaccharide (sucrose), exhibiting a total free sugar concentration of $16.3 \pm 0.4 \mathrm{~g} / 100 \mathrm{~g}$ fw. Glucose and fructose revealed the highest content, presenting values of $8.1 \pm 0.1 \mathrm{~g} / 100 \mathrm{~g}$ fw and $7.8 \pm 0.4 \mathrm{~g} / 100 \mathrm{~g} \mathrm{fw}$, respectively. On the other hand, sucrose showed a much lower concentration, with value of $0.34 \pm 0.02 \mathrm{~g} / 100 \mathrm{~g} \mathrm{fw}$. The obtained sugar profile is in accordance with a previously published study by Milivojevic et al. (2011), which also detected glucose $(6.45 \mathrm{~g} / 100 \mathrm{~g} \mathrm{fw})$, fructose $(7.61 \mathrm{~g} / 100 \mathrm{~g} \mathrm{fw})$ and sucrose $(0.3 \mathrm{~g} / 100 \mathrm{~g} \mathrm{fw})$ in similar concentrations in Rubus fruticosus L. . However, these authors obtained results with lower values in comparison with the present study; as well as, the main free sugar was also different and in this case fructose was the major compound. In a work performed by Barros et al. (2010), studying $R$. ulmifolius flowers, it was also detected the presence of glucose $(0.382 \mathrm{~g} / 100 \mathrm{~g} \mathrm{dw})$, fructose $(0.284 \mathrm{~g} / 100 \mathrm{~g} \mathrm{dw})$, and sucrose $(0.229 \mathrm{~g} / 100 \mathrm{~g} \mathrm{dw})$, but also other sugars, namely, trehalose and raffinose, with values of 0.72 and $0.10 \mathrm{~g}$ / $100 \mathrm{~g} \mathrm{dw}$, respectively; these differences would be expected, because these authors studied another part of this plant.
Furthermore, among other wild red fruits, the composition in sugars are also very similar to Fragaria vesca $L$. and Rubus ideaus L., being also detected as main sugars, glucose, fructose and sucrose. Fructose was predominant in $F$. vesca $(11.68 \mathrm{~g} / 100 \mathrm{~g} \mathrm{fw})$, whereas glucose $(6.52 \mathrm{~g} /$ $100 \mathrm{~g} \mathrm{fw}$ ) was present in the lowest amounts. For $R$. idaeus, with the exception of sucrose $(0.69 \mathrm{~g} / 100 \mathrm{~g} \mathrm{fw})$, it was also obtained lower levels in sugars with $3.83 \mathrm{~g} / 100 \mathrm{~g}$ fw of glucose and $3.15 \mathrm{~g} / 100 \mathrm{~g}$ fw of fructose (Milivojevic et al., 2011). Thus, it was evident that the present study obtained a higher total free sugars value, in comparison with other wild species. These differences could also be explained due to different extraction and analytical procedures, further to the different species studied.

However, despite the higher sugar concentration, it does not mean that blackberries are sweatier, since the content of organic acids is an important factor in the perception of this taste (Milivojevic et al., 2011).

The profile in organic acids was also evaluated and the results are present in Table 2, being identified oxalic, quinic, malic, shikimic, ascorbic, and fumaric acids. According to the results, the total concentration of these molecules was $238 \pm 7 \mathrm{mg} / 100 \mathrm{~g}$ fw. Quinic acid was the compound detected in the highest concentration $(119 \pm 10 \mathrm{mg} / 100 \mathrm{~g} \mathrm{fw})$, followed by oxalic $(71 \pm 4 \mathrm{mg} / 100 \mathrm{~g} \mathrm{fw})$, malic $(29 \pm 1 \mathrm{mg} / 100 \mathrm{~g} \mathrm{fw})$, shikimic $(11.33 \pm 0.05 \mathrm{mg} / 100 \mathrm{~g} \mathrm{fw})$, and ascorbic (6.66 $\pm 0.01 \mathrm{mg} / 100 \mathrm{~g} \mathrm{fw})$, thus fumaric acid was only detected in trace amounts.

Quinic acid has been identified in several fruits and vegetables, and contributes to their characteristic taste (Marrubini, Appelblad, Gazzani, \& Papett, 2015). Some studies have been performed to determine the beneficial effects of this molecule in human health and Papetti et al. (2013) and Conti et al. (2013), described that quinic acid was demonstrated to have an antioxidant potential and act together with other molecules, namely, succinic, oxalic, and shikimic acids as an inhibitor for the most important virulence traits of oral pathogens. Milivojevic et al. (2011) evaluate the difference in chemical properties of cultivated and wild Rubus berries, and with respect to the organic acids profile, only citric (not found in the current analysis) and malic acids were detected. Compared with our study, malic acid was detected in lower amounts, with values of $0.03 \mathrm{mg} / \mathrm{g} \mathrm{fw}$, for example in $R$. fruticosus fruits.

Concerning the fatty acids profile (Table 2), twenty-five compounds were identified, being the most abundant molecule linolenic acid (C18:2n6c) presenting a value of $52.4 \pm 0.5 \%$, followed by $\alpha$-linolenic acid (C18:3n3, $18.6 \pm 0.7 \%)$ and oleic acid (C18:1n9c, $18.4 \pm 0.1 \%)$.

There are several studies that describe these acids with beneficial properties for human health. Linoleic and $\alpha$-linolenic acids are designated as essential fatty acids because humans cannot synthesize them and it is necessary to obtained these fatty acids from the daily diet. Additionally, they are precursors of other substances with important functions in the organism (Anez-Bustillos et al., 2018). Several studies indicate that through linoleic acid (omega $6, \omega-6$ ), it is synthetized the arachidonic acid, a substrate of cyclooxygenase, lipoxygenase and cytochrome P450 enzymes, leading to the generation of eicosanoids and mediators for inflammatory regulation with fundamental physiological functions (Anez-Bustillos et al., 2018; Innes \& Calder, 2018; Mori, 2018; Tallima \& El Ridi, 2018). On the other hand, $\alpha$-linolenic acid (omega 3, $\omega-3)$ is the precursor for the production of others polyunsaturated omega 3 fatty acids, through a cascade of reaction, such as EPA (eicosapentaenoic acid) and DHA (docosahexaenoic acid), which represents the omega 3 fatty acid with major potential to exert beneficial physiologic effects on the regulation of plasma triglyceride levels, arrhythmias, blood pressure, atherosclerotic plaque, platelet aggregation, and consequently, to improve the vascular function (Elagizi et al., 2018). Also, it has the function to control the weight gain and chronic inflammation trough gut microbiota (Zhang, Ju, \& Zuo, 2018).

Other acids detected in a significant concentration were palmitic (C16:0) and stearic (C18:0) acids, showing values of $5.3 \pm 0.2$ and 
Table 2

Individual chemical compounds of $R$. ulmifolius fruits.

\begin{tabular}{|c|c|c|c|c|c|}
\hline Sugars $(\mathrm{g} / 100 \mathrm{~g} \mathrm{fw})$ & & Fatty acids (\%) & & & \\
\hline Fructose & $7.8 \pm 0.4$ & C11:0 & $0.073 \pm 0.001$ & $\mathrm{C} 21: 0$ & $0.023 \pm 0.002$ \\
\hline Glucose & $8.1 \pm 0.1$ & $\mathrm{C} 12: 0$ & $0.10 \pm 0.01$ & $\mathrm{C} 20: 4 \mathrm{n} 6$ & $0.086 \pm 0.001$ \\
\hline Sucrose & $0.34 \pm 0.02$ & $\mathrm{C} 13: 0$ & $0.026 \pm 0.001$ & $\mathrm{C} 20: 3 \mathrm{n} 3$ & $0.026 \pm 0.001$ \\
\hline Total & $16.3 \pm 0.4$ & $\mathrm{C} 14: 0$ & $0.09 \pm 0.01$ & $\mathrm{C} 22: 0$ & $0.33 \pm 0.02$ \\
\hline Organic acids $(\mathrm{mg} / 100 \mathrm{~g} \mathrm{fw})$ & & $\mathrm{C} 15: 0$ & $0.037 \pm 0.001$ & $\mathrm{C} 20: 5 \mathrm{n} 3$ & $0.015 \pm 0.001$ \\
\hline Oxalic acid & $71 \pm 4$ & $\mathrm{C} 16: 0$ & $5.3 \pm 0.2$ & $\mathrm{C} 22: 2$ & $0.029 \pm 0.002$ \\
\hline Quinic acid & $119 \pm 10$ & C16:1 & $0.057 \pm 0.001$ & $\mathrm{C} 24: 0$ & $0.09 \pm 0.01$ \\
\hline Malic acid & $29 \pm 1$ & $\mathrm{C} 17: 0$ & $0.15 \pm 0.01$ & SFA & $9.7 \pm 0.3$ \\
\hline Shikimic acid & $11.33 \pm 0.05$ & $\mathrm{C} 17: 1$ & $0.075 \pm 0.004$ & MUFA & $18.8 \pm 0.1$ \\
\hline Ascorbic acid & $6.66 \pm 0.01$ & C18:0 & $2.94 \pm 0.03$ & PUFA & $71.4 \pm 0.2$ \\
\hline Fumaric acid & $\operatorname{tr}$ & $\mathrm{C} 18: 1 \mathrm{n} 9 \mathrm{c}$ & $18.4 \pm 0.1$ & & \\
\hline Total & $238 \pm 7$ & $\mathrm{C} 18: 2 \mathrm{n} 6 \mathrm{t}$ & $0.110 \pm 0.001$ & & \\
\hline Tocopherols (mg/100 g fw) & & $\mathrm{C} 18: 2 \mathrm{n} 6 \mathrm{c}$ & $52.4 \pm 0.5$ & & \\
\hline$\alpha$-tocopherol & $1.15 \pm 0.04$ & C18:3n6 & $0.069 \pm 0.001$ & & \\
\hline$\beta$-tocopherol & $0.020 \pm 0.002$ & $\mathrm{C} 18: 3 \mathrm{n} 3$ & $18.6 \pm 0.7$ & & \\
\hline$\gamma$-tocopherol & $2.80 \pm 0.04$ & $\mathrm{C} 20: 0$ & $0.63 \pm 0.03$ & & \\
\hline$\delta$-tocopherol & $1.13 \pm 0.04$ & $\mathrm{C} 20: 1$ & $0.27 \pm 0.01$ & & \\
\hline Total & $5.1 \pm 0.1$ & $\mathrm{C} 20: 2$ & $0.038 \pm 0.001$ & & \\
\hline
\end{tabular}

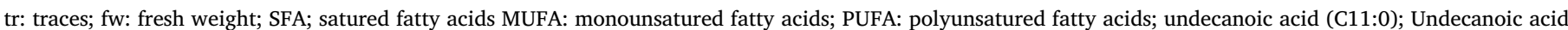

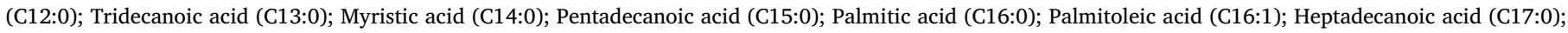

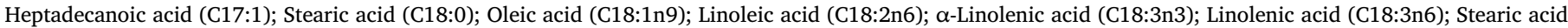

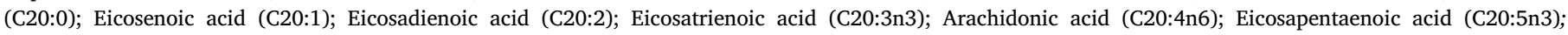
Heneicosanoic acid (C21:0); Behenic acid (C22:0); Docosadienoic acid (C22:2); Lignoceric acid (C24:0). Results are presented as mean \pm SD.

$2.94 \pm 0.03 \%$, respectively. The remaining molecules were detected in concentrations lower than $1 \%$.

A study carried out by Morales et al. (2013), in order to identify potential phytochemicals in wild edible fruits, showed a similarly fatty acid profile to $R$. ulmifolius fruits. These authors also identified linolenic, oleic, and $\alpha$-linolenic acids as the major fatty acids, with concentrations of 48.56, 22.62 and $13.28 \%$, respectively. Compared with the present study, these authors obtained the same major compounds, but linoleic and $\alpha$-linolenic acids showed lower a lower content.

Also Fazio, Plastina, Meijerink, Witkamp, and Gabriele (2013) evaluated the composition and properties of the methanolic extrats of the seed from two wild fruits (Rubus ulmifolius Schott and Sambucus nigra $L$.) and the analysis showeded that the most represented fatty acids in $R$. ulmifolius seeds were linolenic $\left(15.34 \mathrm{~g} / 100 \mathrm{~g}_{\text {oil }}\right), \alpha$-linolenic $\left(4.22 \mathrm{~g} / 100 \mathrm{~g}_{\mathrm{oil}}\right)$ and oleic acids $\left(8.33 \mathrm{~g} / 100 \mathrm{~g}_{\mathrm{oil}}\right)$. These authors also detected the same main compounds; however, the values cannot be compared because they are expressed in different units. Moreover, Barros et al. (2010) performed a study regarding the phytochemical composition of flowers and flowers buds from $R$. ulmifolius and detected 23 fatty acids, being $\alpha$-linolenic (38.04\%, 39.56\%), linolenic (14.98\%, $16.02 \%)$, and palmitic acids $(12.05 \%, 11.99 \%)$ the most abundant fatty acids.

In a general, polyunsaturated fatty acids (PUFA $-71.4 \pm 0.2 \%$ ) were the predominant compounds, followed by monounsaturated fatty acids (MUFA $-18.8 \pm 0.1 \%$ ) and saturated fatty acids (SFA $9.7 \pm 0.3 \%$ ). These results are in accordance with the other studies previously reported, namely, in Fazio et al. (2013) presenting a higher percentage in PUFA (19.56\%) compared to SFA (3.47\%) in the seed oil of these fruits, and in Barros et al. (2010) with a percentage of $53.56 \%$ of PUFA and $42.99 \%$ of SFA. This latter study shows lower PUFA values in comparison to the present study, thus the SFA values were considerably higher.

The ration between PUFA/SFA is a factor to evaluate the nutritional quality of food products, this ratio should present values over 0.45 (Ospina-E et al., 2012; Morales et al., 2013; Rincón-Cervera et al., 2019). Therefore, in the studied fruits, the ratio presented a value of 7.40, which present the quality of this fruit.

The analysis of tocopherols is present in Table 2, and several isoforms were detected, namely, $\alpha$-, $\beta$-, $\gamma$ - and $\delta$-tocopherol, presenting a total tocopherol content of $5.1 \pm 0.1 \mathrm{mg} / 100 \mathrm{~g}$ fw. $\gamma$-Tocopherol was highlighted as a major isoform present in analysed samples, with a concentration of $2.80 \pm 0.04 \mathrm{mg} / 100 \mathrm{~g} \mathrm{fw}$, followed by $\alpha$-tocopherol, and $\delta$-tocopherol with similar contents, $1.15 \pm 0.04 \mathrm{mg} / 100 \mathrm{~g}$ fw and $1.13 \pm 0.04 \mathrm{mg} / 100 \mathrm{~g} \mathrm{fw}$, respectively. $\beta$-Tocopherol was detected in the lowest concentration with value of $0.020 \pm 0.002 \mathrm{mg} / 100 \mathrm{~g} \mathrm{fw} . \gamma$ Tocopherol has been reported as a very potent compound in delaying arterial thrombus formation, reducing LDL oxidation, superoxide generation and lipid peroxidation. It has also been mentioned that regular consumption of food rich in this isoform lowers the risk of myocardial infarction and death from ischemic heart disease (Nadeem et al., 2012). Campbell, Stone, Whaley, and Krishnan (2003) has also reported that most of the antioxidant and protective effects of tocopherols have been focused primarily on $\alpha$-tocopherol, which is the main form of vitamin E, in over-the-counter supplements. This isoform was second most abundant in the fruits of $R$. ulmifolius.

The obtained results are in accordance with a study performed by Morales et al. (2013), which detecting a total tocopherol content of $13.48 \mathrm{mg} / 100 \mathrm{~g} \mathrm{fw}$ in wild edible fruits, with similar contents of $\gamma$-tocopherol (3.73 mg/100 g fw), $\delta$-tocopherol ( $3.69 \mathrm{mg} / 100 \mathrm{~g} \mathrm{fw}$ ), and $\alpha$ tocopherol $(3.38 \mathrm{mg} / 100 \mathrm{~g} \mathrm{fw})$ and lower amount of $\beta$-tocopherol $(0.24 \mathrm{mg} / 100 \mathrm{~g} \mathrm{fw})$. In comparison to our results, these authors obtained higher concentrations of all isoforms and, consequently, of total tocopherols. In a study performed by Fazio et al. (2013) using seed oils of R. ulmifolius fruits, showed a total tocopherol content of $43.71 \mu \mathrm{g} /$ $\mathrm{g}_{\text {oil }}$, being $\gamma$-tocopherol $\left(43.35 \mu \mathrm{g} / 100 \mathrm{~g}_{\text {oil }}\right)$ the highest isoform found, whereas $\alpha$-tocopherol $\left(0.36 \mu \mathrm{g} / 100 \mathrm{~g}_{\text {oil }}\right)$ was detected in lowest amount, and $\beta$-tocopherol and $\delta$-tocopherol were not detected. In this study, although the results were not expressed in the same unit, it was possible to concluded that there was a significant heterogeneity between the detected isoforms in comparison to the present study. Barros et al. (2010), detected the presence of all tocopherol isoforms ( $\alpha-, \beta-, \gamma$ and $\delta$-tocopherol) in the $R$. ulmifolius flowers buds and open flowers, with a total content of $12.28 \mathrm{mg} / 100 \mathrm{~g} \mathrm{dw}$ and $9.86 \mathrm{mg} / 100 \mathrm{~g} \mathrm{dw}$, respectively; and the major isoform found was $\alpha$-tocopherol presenting values of $5.97 \mathrm{mg} / 100 \mathrm{~g} \mathrm{dw}$ and $5.84 \mathrm{mg} / 100 \mathrm{~g} \mathrm{dw}$, respectively. However, in this study there were a discrepancy of the results in comparison to our results, thus these differences would be expected due to the different parts of this species studied. 
Table 3

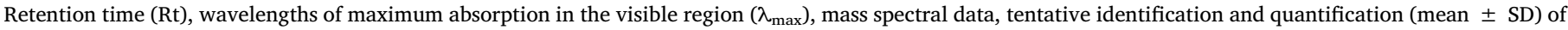
non-anthocyanin and anthocyanin compounds of $R$. ulmifolius fruits.

\begin{tabular}{|c|c|c|c|c|c|c|}
\hline \multirow[t]{2}{*}{ Peak } & \multirow{2}{*}{$\frac{\mathrm{Rt}}{(\mathrm{min})}$} & \multirow{2}{*}{$\frac{\lambda_{\max }}{(\mathrm{nm})}$} & \multirow[t]{2}{*}{ Tentative identification } & \multirow[t]{2}{*}[\mathrm{M}-\mathrm{H}]{$^{-}$} & Main fragment & \multirow[t]{2}{*}{ Quantification (mg/g extract) } \\
\hline & & & & & ESI- MS ${ }^{\mathrm{n}}$ [intensity (\%)] & \\
\hline 1 & 5.58 & 320 & Caffeic acid hexoside & 341 & $\mathrm{MS}^{2}[341]: 179(100)$ & $1.6 \pm 0.1$ \\
\hline 2 & 6.72 & 324 & $4-O-C Q A$ & 353 & $\mathrm{MS}^{2}$ [353]: 191(12),179(51),173(100),155(8),135(5) & $3.1 \pm 0.1$ \\
\hline 3 & 7.97 & - & Taxifolin-O-hexoside isomer 1 & 465 & $\operatorname{MS}^{2}[465]: 303(100)$ & $2.3 \pm 0.1$ \\
\hline 4 & 9.62 & - & Eriodictyol-O-hexoside & 449 & $\mathrm{MS}^{2}$ [449]: 287(100) & $0.94 \pm 0.02$ \\
\hline 5 & 11.05 & 343 & Kaempferol-O-di-hexoside & 609 & $\mathrm{MS}^{2}[609]: 285(100)$ & $1.18 \pm 0.02$ \\
\hline 6 & 14.48 & 285 & Sanguiin $\mathrm{H}-10$ & 1567 & $\operatorname{MS}^{2}$ [1567]: 1265(11),1235(23),1103(5),935(7),783(12),633(48),301(41) & $9.6 \pm 0.1$ \\
\hline 7 & 17.66 & 360 & Ellagic acid pentoside & 433 & $\mathrm{MS}^{2}$ [433]: $301(100)$ & $13.2 \pm 0.4$ \\
\hline 8 & 18.20 & 361 & Ellagic acid glucuronide & 477 & $\mathrm{MS}^{2}$ [477]: 301(100) & $10.7 \pm 0.1$ \\
\hline 9 & 18.95 & 278,328 & Taxifolin-O-hexoside isomer 2 & 465 & $\operatorname{MS}^{2}[465]: 303(100)$ & $1.60 \pm 0.02$ \\
\hline 10 & 20.84 & 355 & Quercetin-HMG-glucoside & 607 & $\operatorname{MS}^{2}$ [607]: 463(53), 301(100) & $2.1 \pm 0.1$ \\
\hline \multirow[t]{5}{*}{11} & 23.68 & 355 & Quercetin-HMG-rhamnoside & 591 & $\mathrm{MS}^{2}$ [591]: 447(47), 301(100) & $1.55 \pm 0.02$ \\
\hline & & & & & TPA & $28.7 \pm 0.7$ \\
\hline & & & & & TFNA & $9.68 \pm 0.03$ \\
\hline & & & & & TE & $9.6 \pm 0.1$ \\
\hline & & & & & TPCNA & $47.9 \pm 0.8$ \\
\hline
\end{tabular}

\begin{tabular}{|c|c|c|c|c|c|c|}
\hline \multirow[t]{2}{*}{ Peak } & Rt & $\lambda \max (\mathrm{nm})$ & Tentative identification & {$[\mathrm{M}+\mathrm{H}]^{+}$} & Main fragment & (mg/g extract) \\
\hline & \multicolumn{4}{|l|}{$(\min )$} & \multicolumn{2}{|l|}{ ESI- MS ${ }^{\mathrm{n}}$ [intensity (\%)] } \\
\hline 12 & 27.61 & 517 & Cyanidin-O-di-hexoside & 611 & $287(100)$ & $2.14 \pm 0.02$ \\
\hline 13 & 29.02 & 516 & Cyanidin-3-O-glucoside & 449 & $287(100)$ & $14.69 \pm 0.04$ \\
\hline 14 & 31.08 & 502 & Pelargonidin-3-O-glucoside & 433 & $271(100)$ & $2.234 \pm 0.003$ \\
\hline 15 & 32.05 & 518 & Cyanidin-3-O-xyloside & 419 & $287(100)$ & $2.62 \pm 0.02$ \\
\hline \multirow[t]{2}{*}{16} & 32.52 & 519 & Cyanidin-3-O-dioxayl-glucoside & 593 & $287(100)$ & $2.04 \pm 0.03$ \\
\hline & & & & & TAC & $23.7 \pm 0.1$ \\
\hline
\end{tabular}

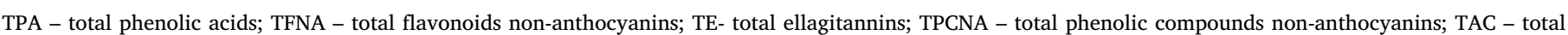

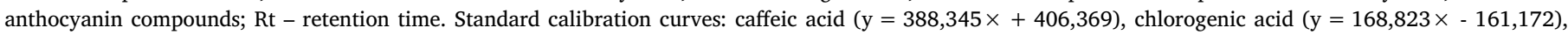

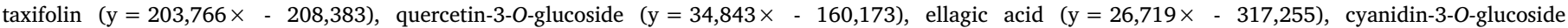
$(y=104,478 \times-823,429)$, pelargonidin-3-O-glucoside $(y=50,652 \times-696,848)$. Results of quantification are presented as mean \pm SD.

\subsection{Phenolic composition of R. ulmifolius fruits}

Results regarding the phenolic compounds profile of $R$. ulmifolius fruit extracts are present in Table 3. The evaluated extract revealed the presence of eleven non-anthocyanin (4 phenolic acids, 2 dihydroflavonol, three flavonol, oneflavanone, and a ellagitanin) and five anthocyanin (cyanidin and pelargonidin glycoside derivatives) compounds (Fig. 1).

The identification of these compounds were performed taking into account the retention time, UV-Vis spectra, and mass fragmentation pattern. Regarding the non-anthocyanin compounds, peaks 1, 2, 7, and 8 were identified as phenolic acids. Peak $1\left([\mathrm{M}-\mathrm{H}]^{-}\right.$at $\left.m / z 341\right)$ released an $\mathrm{MS}^{2}$ fragment at $m / z 179$ ([caffeic acid-H] ${ }^{-}$) from the loss of a hexosyl moiety $(-162 \mathrm{u})$ being tentatively identified as caffeic acid hexoside. Peak $2\left([\mathrm{M}-\mathrm{H}]^{-}\right.$at $\left.m / z 353\right)$ was identified as caffeoyl-quinic acid, and considering the fragmentation pattern described by Clifford, Johnston, Knight, and Kuhnert (2005), it was identified as 4-O-caffeoylquinic acid. Compounds $7\left([\mathrm{M}-\mathrm{H}]^{-}\right.$at $\left.\mathrm{m} / \mathrm{z} 433\right)$ and $8\left([\mathrm{M}-\mathrm{H}]^{-}\right.$at $\mathrm{m} / \mathrm{z}$ 477) both presented UV-Vis spectra similar to ellagic acid and

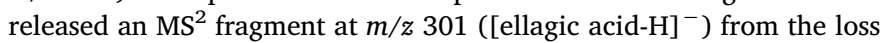
of a pentosyl ( $-132 \mathrm{u})$ and glucuronyl moiety, respectively, being tentatively assigned as ellagic acid pentoside and ellagic acid glucuronide. Compound $6\left([\mathrm{M}-\mathrm{H}]^{-}\right.$at $\left.m / z 1567\right)$ was the only hydrosoluble tannin found in the fruits of $R$. ulmifolius being identified as sanguiin $\mathrm{H}$ 10. This identification was made taking into account its previous fragmentation pattern described by the authors in R. ulmifolius flowers buds and open flowers (Martins et al., 2014).

Compounds 3-5 and 9-11 were identified as non-anthocyanin flavonoid glycosides. Peaks 3 and $9\left([\mathrm{M}-\mathrm{H}]^{-}\right.$at $\left.m / z 465\right)$ presented the same pseudomolecular ion and were identified as taxifolin derivatives, revealing an $\mathrm{MS}^{2}$ fragment released at $\mathrm{m} / \mathrm{z} 303$ (taxifolin; [M-H-162] ${ }^{-}$ loss of a hexosyl moiety), being tentatively assigned as taxifolin-Ohexoside isomers. Considering similar reasoning, peaks $4\left([\mathrm{M}-\mathrm{H}]^{-}\right.$at $m / z 449)$ and $5\left([\mathrm{M}-\mathrm{H}]^{-}\right.$at $\left.m / z 609\right)$ were identified as eriodictyol-Ohexoside and kaempferol-O-di-hexoside, respectively. Compound 10 $\left([\mathrm{M}-\mathrm{H}]^{-}\right.$at $\left.m / z 607\right)$ and $11\left([\mathrm{M}-\mathrm{H}]^{-}\right.$at $m / z$ 591) was identified as quercetin-HMG-glucoside and quercetin-HMG-rhamnoside considering previous findings found in other Rubus sp. (McDougall, Martinussen, Junttila, Verrall, \& Stewart, 2011; Tavares et al., 2012)

Ellagic acid pentoside $(13.2 \pm 0.4 \mathrm{mg} / \mathrm{g}$ of extract) followed by ellagic acid glucuronide $(10.7 \pm 0.1 \mathrm{mg} / \mathrm{g}$ of extract $)$ and sanguiin $\mathrm{H}$ $10(9.6 \pm 0.1 \mathrm{mg} / \mathrm{g}$ of extract) were the main non-anthocyanin compounds. Besides ellagic acid derivatives, moderate quantities of caffeic acid derivatives (peak 1 and 2) and non-anthocyanin flavonoid glycosides (peaks 3, 4, 5, 9, 10 and 11) were also found in $R$. ulmifolius fruit extracts, accounting to 10 and $20 \%$, respectively of the phenolic compounds composition. The phenolic compounds of $R$. ulmifoius fruits has been previously described by Ruiz-Rodríguez et al. (2014) in a sample from Spain, nevertheless, the phenolic profile shown by these authors is completely different from the one obtained herein.

Regarding the anthocyanin compounds, peaks 13 (cyanidin-3-Oglucoside) and 14 (pelargonidin-3-O-glucoside) were positively identified with commercial standards. Compound $12\left([\mathrm{M}+\mathrm{H}]^{+}\right.$at $\left.m / z 611\right)$ presented an $\mathrm{MS}^{2}$ fragment released at $m / z 287$ (cyanidin; [M $+\mathrm{H}-162$ $162]^{-}$loss of a two hexosyl moieties), thus being identified as a cyanidin-O-di-hexoside. Peak $15\left([\mathrm{M}+\mathrm{H}]^{+}\right.$at $\mathrm{m} / \mathrm{z}$ 419) and 16 $\left([\mathrm{M}+\mathrm{H}]^{+}\right.$at $\left.m / z 593\right)$ were assigned to a cyanidin-3-O-xyloside and cyanidin-3-O-dioxayl-glucoside, owing to the identification of those 


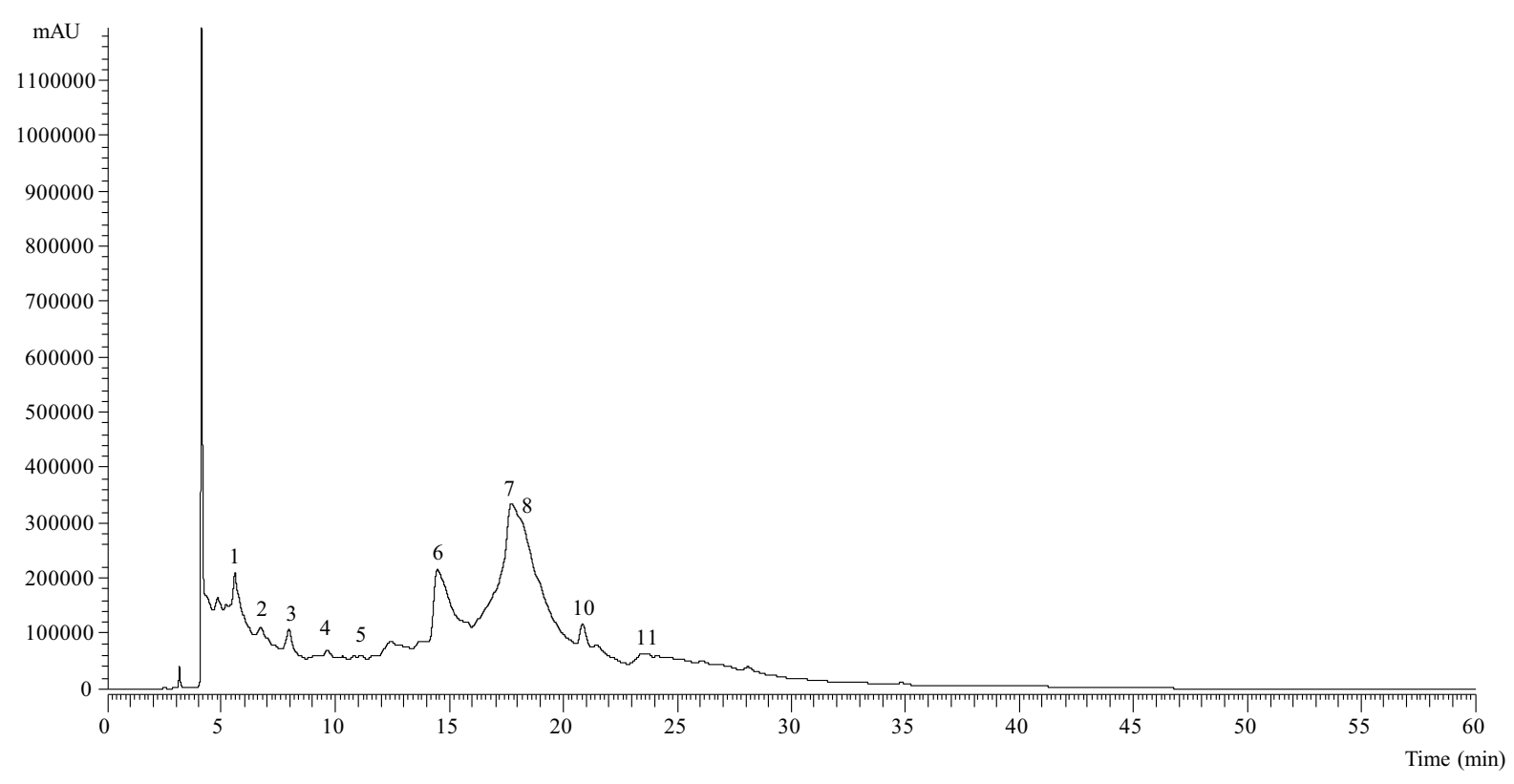

A

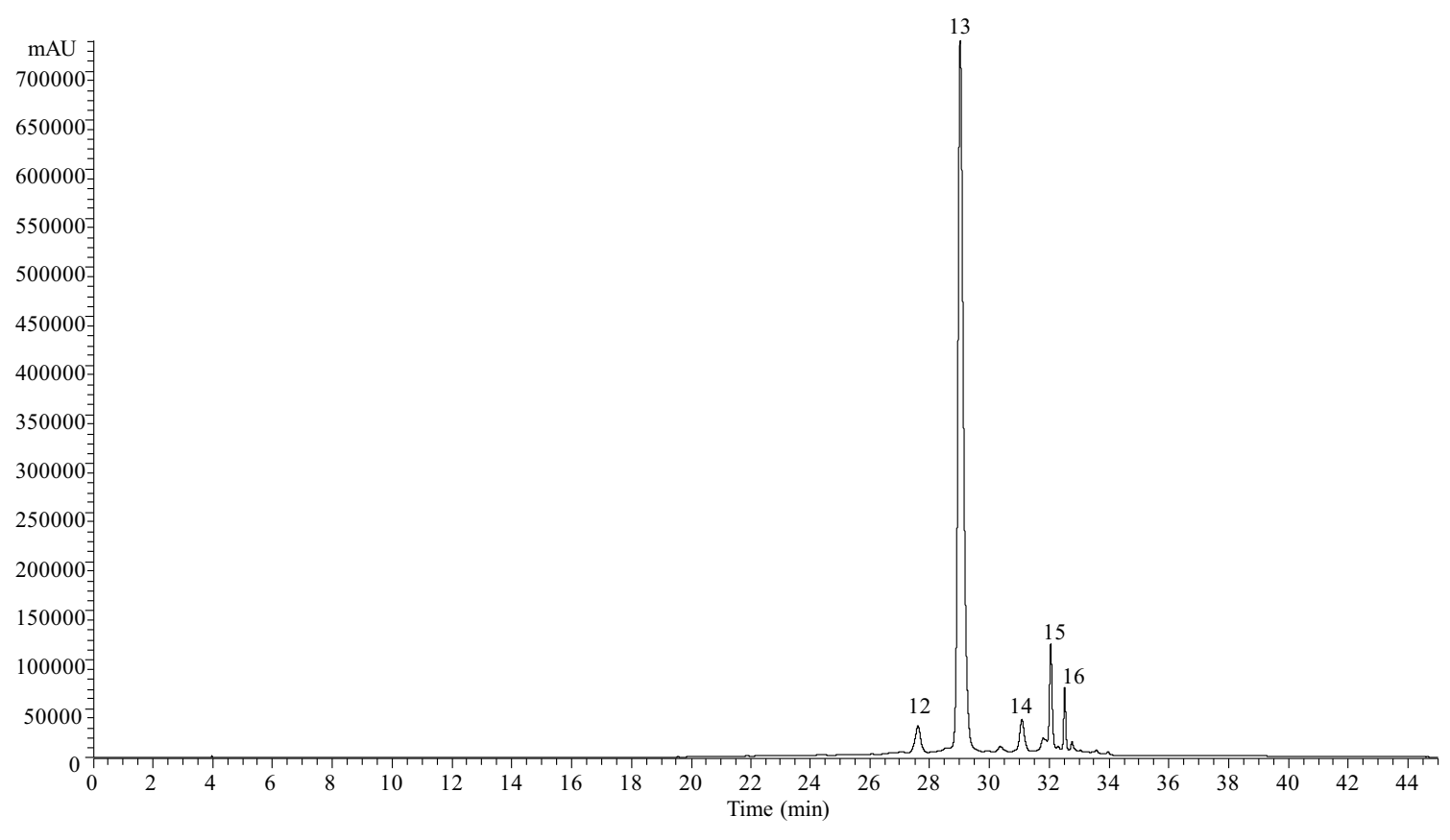

B

Fig. 1. Phenolic compounds of R. ulmifolius fruits recorded at 280 (A) and 520 (B) nm. The numbers correspond to the peaks identified in Table 3.

compounds in blackberries by Tavares et al. (2012).

The main phenolic compounds found in $R$. ulmifolius fruits were anthocyanins (23.8 $\pm 0.1 \mathrm{mg} / \mathrm{g}$ extract), representing about $35 \%$ of the total phenolic compounds quantified, comprising different cyanidin glycosides and one pelargonidin glycoside, with the higher amounts being found for cyanidin-3-O-glucoside $(14.7 \mathrm{mg} / \mathrm{g}$ extract). This compound has been previous reported as the main anthocyanin compound in fruits of the same species (Ruiz-Rodríguez et al., 2014). Thus, none of the remainig anthocyanin compounds have been descrided, which could be explain for different location of the fruit origin.

\subsection{Antimicrobial activity}

The results obtained for the antimicrobial activity in hydroethanolic extracts of R. ulmifolius fruits are present in Table 4. The results obtained in this study revealed activity in some tested strains, with MIC values ranging between 5 and $>20 \mathrm{mg} / \mathrm{mL}$. Among the tested bacteria, the sample revealed a potential bacteriostatic effect against most of the studied strains, with the exception of Klebsiella pneumoniae and Pseudomonas aeruginosa (both Gram-negative bacteria), being necessary a concentration above $20 \mathrm{mg} / \mathrm{mL}$ for the inhibition of their microbial growth. For the remaining Gram-negative strains, the most effective results were shown against Morganella morganii (MIC $=5 \mathrm{mg} / \mathrm{mL}$ ) and Escherichia coli (MIC $=5 \mathrm{mg} / \mathrm{mL}$ ), followed by Proteus mirabilis $(10 \mathrm{mg}$ / 
Table 4

Antibacterial (MIC and MBC- $\mathrm{mg} / \mathrm{mL}$ ) activity of the hydroethanolic extract of $R$. ulmifolius fruits.

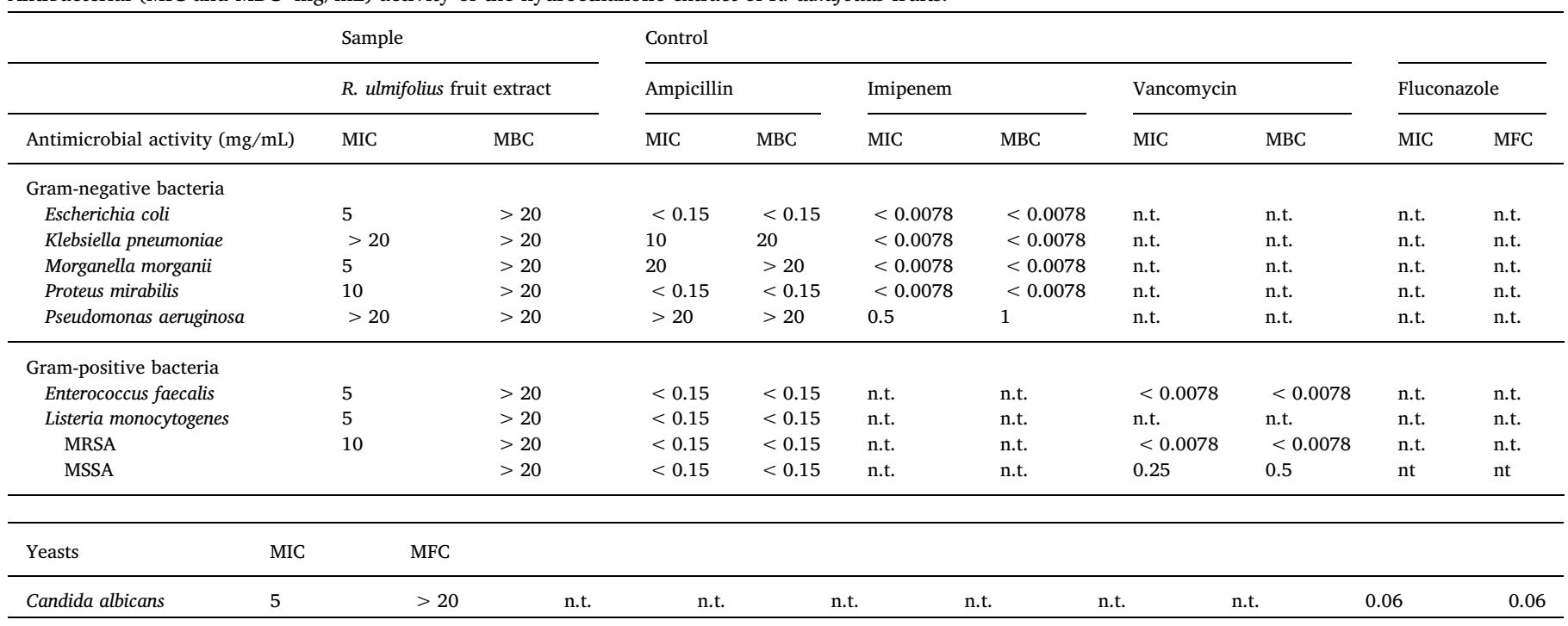

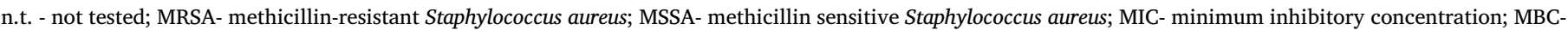
minimum bactericidal concentration; MFC - minimum fungicidal concentration.

$\mathrm{mL})$, being the first one more active than ampicillin $(20 \mathrm{mg} / \mathrm{mL})$ used as a positive control. Concerning Gram-positive bacteria, the extract also exhibited a bacteriostatic effect against all the tested strains, Enterococcus faecalis, Listeria monocytogenes, and MSSA were the most susceptible to the extract (MIC $=5 \mathrm{mg} / \mathrm{mL}$ ), followed by MRSA (MIC $=10 \mathrm{mg} / \mathrm{mL}$ ).

Gomes et al. (2018) evaluated the antibacterial activity of the hydromethanolic extracts of flower buds and fully opened flowers of $R$. ulmifolius against different Staphylococcus aureus strains. These authors revealed that the extracts had moderate effects against $S$. aureus, resulting in a inhibition halo ranging from 8 to $10 \mathrm{~mm}$, which means that the extract had a bacteriostatic effect. However, in a study performed by Hajaji et al. (2017), who evaluate several bioactivities of a Tunisian $R$. ulmifolius methanolic extract, through the disc diffusion assay, no significant results were reached against $S$. aureus.

Thus, the results obtained herein for the studied extracts are very promising, since the tested microorganism were clinical isolates with a large resistant spectrum. These results could be associated to the phenolic composition found in the studied extracts.

Mingo, Silván, \& Martinez-Rodriguez (2016) suggested that the phenolic compounds composition was also strongly involved in the antimicrobial effect. However, they are unable to associate the activity to a specific compound, due to the capacity of phenolic compounds to act synergistically. However, they suggested that epicatechin gallate could be the most active compound as it showed the lowest value of MIC and MBC. Also, these authors also concluded that the potential activity of this compound could be related to the gallate side chain, which when bonded to a bacterial lipid bilayer cell membrane, it is capable to cause damage or dysfunction of the membrane. In a similar context Bittencourt et al. (2015), study a brazilian propolis in order to identify the bioactive potential of its compounds (total phenolic compounds, triterpenoids, acetyltriterpenoids, sesquiterpenes, steroids, and hydrocarbons) and the respective activity (antimicrobial and antioxidant activities). The authors detected a good correlation between some of the detected compounds and the obtained antimicrobial activity, suggesting that in some cases, the activities could be achieved by synergistic effects among the potential compounds present in the extract.

On the other hand, Kemperman, Bolca, Roger, and Vaughan (2010) analysed the mechanisms of microbial inhibition exerted by phenolic compounds, and according to these results, the authors stated that polyphenols may act as antimicrobial agents through phenolic-membrane interactions, DNA gyrase inhibition, and metal sequester. Also, the mechanisms could be associated to a structural change in the bacteria, as these compounds promote the penetration of the drug in to the bacterial membrane, inhibiting the action of protective enzymes and interfere with metabolic targets of the antibiotic, which are associated to multiple resistance of bacteria (Albano et al., 2016).

For the tested fungi, Candida albicans, the extract also exhibited a fungistatic effect (MIC $=5 \mathrm{mg} / \mathrm{mL}$ ). The positive effect against $C$. albicans was also support by a study performed by Panizzi, Caponi, Catalano, Cioni, and Morelli (2002), which aimed to evaluate the antimicrobial activity of $R$. ulmifolius extracts (leaves, branches and flowering tops), from Italy, obtained using solvents with different polarity, which showed to be more effective when extracted with methanol and less effective when water was applied as the solvent.

On the other hand, in the present study the extract did not show a sufficient bactericidal and fungicidal effect in order to eliminate the strains, absence of MBC and MFC, although promoting a bacteriostatic and fungistatic effect in most of the tested strains.

A study performed by Hajaji et al. (2017), who aimed to evaluate several bioactivities of the methanolic extract of $R$. ulmifolius fruits from Tunisia, concluded that they have a potential bacteriostatic and bactericidal effect. These authors used the diffusion agar test, where the extracts showed a bacteriostatic effect against Escherichia coli ATCC 8739 and Candida albicans (inhibition halos of $28 \mathrm{~mm}$ and $39 \mathrm{~mm}$, respectively). Moreover, through the broth dilution method, they obtained MIC and MBC values, which showed similar values in relation to the present study, namely, against E. coli ATCC 8739 (MIC $=4.03 \mathrm{mg}$ / $\mathrm{mL} ; \mathrm{MBC}=8.92 \mathrm{mg} / \mathrm{mL}$ ). Positive results were also obtained against $S$. aureus (MIC $=3.22 \mathrm{mg} / \mathrm{mL} ; \quad \mathrm{MBC}=7.17 \mathrm{mg} / \mathrm{mL}$ ) and $C$. albicans ( $\mathrm{MIC}=3.17 \mathrm{mg} / \mathrm{mL} ; \mathrm{MBC}=7.25 \mathrm{mg} / \mathrm{mL}$ ). Some differences observed between different studies can be explained by the different geographic localization, which leads to different environmental conditions, namely, climate, soil, among others, that have a high impact in the chemical composition of these species. Furthermore, the extraction solvents applied, have also high impact in their chemical composition and consequently is responsible for expressing distinct bioactivities (Dai, Gupte, Gates, \& Mumper, 2009; Hajaji et al., 2017).

Concerning the toxicity assay, through the primary cell culture PLP2, the extracts did not show toxicity, obtaining values of $\mathrm{GI}_{50}>400 \mu \mathrm{g} / \mathrm{mL}$. 


\section{Conclusions}

R. ulmifolius is a fruit appreciated by consumers and is described as a food with several health benefits. In this study the nutritional and chemical characterization was carried out, as well as the antimicrobial activity.

The nutritional profile revealed that the blackberry is an energetic fruit, being carbohydrates the most abundant macronutrient. Their chemical composition revealed glucose as the predominate sugar molecule present, while quinic acid showed the greatest amount, regarding organic acids. These characteristics justify the sweetish and slight acid characteristic taste of blackberry. In the fatty acid evaluation, 25 fatty acids were identified and the profile evidenced a great PUFA/SFA ratio, that is known to maintain plasma cholesterol concentrations and consequently, reduce the risk of several cardiovascular diseases. Moreover, the fruits revealed the presence of all tocopherols isoforms, highlighting $\alpha$ - and $\delta$-tocopherol with higher concentrations. Whilst anthocyanins represent about $35 \%$ of the total phenolic compounds quantified, being cyaniding-3-O-glucoside the major compound present, followed by ellagic acid pentoside, ellagic acid glucuronide and sanguiin H-10. Concerning, the antimicrobial activity fruits showed a bacteriostatic and fungistatic effect, being a natural source to explore and to obtain greater effectiveness for further applications as an antimicrobial agent. Based on the obtained results, $R$. ulmifolius fruits showed to be a good choice to enrich the daily diet, due to it nutritional and chemical composition.

\section{Conflict of interest}

The authors declare they have no conflict of interest.

\section{Acknowledgements}

The authors are grateful to the Foundation for Science and Technology (FCT, Portugal) and FEDER under Program PT2020 for financial support to CIMO (UID/AGR/00690/2013), L. Barros and R. Calhelha contracts. The authors are also grateful to the Interreg EspañaPortugal for financial support through the project 0377_Iberphenol_6_E). This work is also funded by the European Structural and Investment Funds (FEEI) through the Regional Operational Program North 2020, within the scope of Project NORTE01-0145-FEDER-023289: DeCodE and project Mobilizador Norte-010247-FEDER-024479: ValorNatural ${ }^{\circledR}$. The authors also thank Professor of Botany Carlos Aguiar for the help given for the plant material collection and botanical identification.

\section{References}

Albano, M., Alves, F. C. B., Andrade, B. F. M. T., Barbosa, L. N., Pereira, A. F. M., de Lourdes Ribeiro, M., de da Souza, C., ... Fernandes Júnior, A. (2016). Antibacterial and anti-staphylococcal enterotoxin activities of phenolic compounds. Innovative Food Science and Emerging Technologies, 38, 83-90.

Alves, M. J., Ferreira, I. C. F. R., Martins, A., \& Pintado, M. (2012). Antimicrobial activity of wild mushroom extracts against clinical isolates resistant to different antibiotics. Journal of Applied Microbiology, 113, 466-475.

Anez-Bustillos, L., Dao, D. T., Fell, G. L., Baker, M. A., Gura, K. M., Bistrian, B. R., \& Puder, M. (2018). Redefining essential fatty acids in the era of novel intravenous lipid emulsions. Clinical Nutrition, 37, 784-789.

Asioli, D., Aschemann-Witzel, J., Caputo, V., Vecchio, R., Annunziata, A., Næs, T., \& Varela, P. (2017). Making sense of the "clean label" trends: A review of consumer food choice behavior and discussion of industry implications. Food Research International, 99, 58-71.

Bacchetta, L., Visioli, F., Cappelli, G., Caruso, E., Martin, G., Nemeth, E., ... Eatwild Consortium (2016). A manifesto for the valorization of wild edible plants. Journal of Ethnopharmacology, 191, 180-187.

Barros, L., Oliveira, S., Carvalho, A. M., \& Ferreira, I. C. F. R. (2010). In vitro antioxidant properties and characterization in nutrients and phytochemicals of six medicinal plants from the Portuguese folk medicine. Industrial Crops and Products, 32, 572-579.

Barros, L., Pereira, C., \& Ferreira, I. C. F. R. (2013). Optimized analysis of organic acids in edible mushrooms from Portugal by ultra fast liquid chromatography and photodiode array detection. Food Analytical Methods, 6, 309-316.
Barros, L., Pereira, E., Calhelha, R. C., Dueñas, M., Carvalho, A. M., Santos-Buelga, C., \& Ferreira, I. C. F. R. (2013). Bioactivity and chemical characterization in hydrophilic and lipophilic compounds of chenopodium ambrosioides L. Journal of Functional Foods, 5, 1732-1740.

Bessada, S. M. F., Barreira, J. C. M., Barros, L., Ferreira, I. C. F. R., \& Oliveira, M. B. P. P. (2016). Phenolic profile and antioxidant activity of Coleostephus myconis (L.) Rchb.F.: An underexploited and highly disseminated species. Industrial Crops and Products, 89, 45-51.

Bittencourt, M. L. F., Ribeiro, P. R., Franco, R. L. P., Hilhorst, H. W. M., de Castro, R. D., \& Fernandez, L. G. (2015). Metabolite profiling, antioxidant and antibacterial activities of Brazilian propolis: Use of correlation and multivariate analyses to identify potential bioactive compounds. Food Research International, 76, 449-457.

Campbell, S., Stone, W., Whaley, S., \& Krishnan, K. (2003). Development of gamma ( $\gamma$ )tocopherol as a colorectal cancer chemopreventive agent. Critical Reviews in Oncology/Hematology, 47, 249-259.

Clifford, M. N., Johnston, K. L., Knight, S., \& Kuhnert, N. A. (2005). Discriminating between the six isomers of dicaffeoylquinic acid by LC-MSn. Journal of Agricultural and Food Chemistry, 53, 3821-3832.

Conti, B., Colzani, B., Papetti, A., Mascherpa, D., Dorati, R., Genta, I., ... Gazzani, G. (2013). Adhesive microbeads for the targeting delivery of anticaries agents of vegetable origin. Food Chemistry, 138, 898-904.

D'Agostino, M. F., Sanz, J., Sanz, M. L., Giuffrè, A. M., Sicari, V., \& Soria, A. C. (2015). Optimization of a solid-phase microextraction method for the gas chromatographymass spectrometry analysis of blackberry (Rubus ulmifolius Schott) fruit volatiles. Food Chemistry, 178, 10-17.

Dai, J., Gupte, A., Gates, L., \& Mumper, R. J. (2009). A comprehensive study of anthocyanin-containing extracts from selected blackberry cultivars: Extraction methods, stability, anticancer properties and mechanisms. Food and Chemical Toxicology, 47, $837-847$.

De Souza, V. R., Pereira, P. A. P., Da Silva, T. L. T., De Oliveira Lima, L. C., Pio, R., \& Queiroz, F. (2014). Determination of the bioactive compounds, antioxidant activity and chemical composition of Brazilian blackberry, red raspberry, strawberry, blueberry and sweet cherry fruits. Food Chemistry, 156, 362-368.

Elagizi, A., Lavie, C. J., Marshall, K., DiNicolantonio, J. J., O'Keefe, J. H., \& Milani, R. V. (2018). Omega-3 polyunsaturated fatty acids and cardiovascular health: A comprehensive review. Progress in Cardiovascular Diseases, 61, 76-85.

Emilia, M., \& Accame, C. (2016). Frutos Con Interés En Farmacia: Grosellas. ISSN 0210-1394. vol. $40\left(\mathrm{~N}^{\circ} .392\right)$

Fazio, A., Plastina, P., Meijerink, J., Witkamp, R. F., \& Gabriele, B. (2013). Comparative analyses of seeds of wild fruits of Rubus and Sambucus species from Southern Italy: Fatty acid composition of the oil, total phenolic content, antioxidant and anti-inflammatory properties of the methanolic extracts. Food Chemistry, 140, 817-824.

Gomes, F., Martins, N., Barros, L., Rodrigues, M. E., Oliveira, M. B. P. P., Henriques, M., \& Ferreira, I. C. F. R. (2018). Plant phenolic extracts as an effective strategy to control staphylococcus aureus, the dairy industry pathogen. Industrial Crops and Products, $112,515-520$.

Gonçalves, G. A., Soares, A. A., Correa, R. C. G., Barros, L., Haminiuk, C. W. I., Peralta, R. M., ... Bracht, A. (2017). Merlot grape pomace hydroalcoholic extract improves the oxidative and inflammatory states of rats with adjuvant-induced arthritis. Journal of Functional Foods, 33, 408-418.

Hajaji, S., Jabri, M. A., Sifaoui, I., López-Arencibia, A., Reyes-Batlle, M., B'chir, F., ... Akkari, H. (2017). Amoebicidal, antimicrobial and in vitro ROS scavenging activities of Tunisian Rubus ulmifolius Schott, methanolic extract. Experimental Parasitology, 183, 224-230.

Kaume, L., Howard, L. R., \& Devareddy, L. (2012). The blackberry fruit: A review on its composition and chemistry, metabolism and bioavailability, and health benefits. Journal of Agricultural and Food Chemistry, 60, 5716-5727.

Kemperman, R. A., Bolca, S., Roger, L. C., \& Vaughan, E. E. (2010). Novel approaches for analysing gut microbes and dietary polyphenols: Challenges and opportunities. Microbiology, 156, 3224-3231.

Marrubini, G., Appelblad, P., Gazzani, G., \& Papett, A. (2015). Determination of free quinic acid in food matrices by hydrophilic interaction liquid chromatography with UV detection. Journal of Food Composition and Analysis, 44, 80-85.

Martins, A., Barros, L., Carvalho, A. M., Santos-Buelga, C., Fernandes, I. P., Barreiro, F., \& Ferreira, I. C. F. R. (2014). Phenolic extracts of Rubus ulmifolius Schott flowers: Characterization, microencapsulation and incorporation into yogurts as nutraceutical sources. Food and Function, 5, 1091-1100.

McDougall, G. J., Martinussen, I., Junttila, O., Verrall, S., \& Stewart, D. (2011). Assessing the influence of genotype and temperature on polyphenol composition in cloudberry (Rubus chamaemorus L.) using a novel mass spectrometric method. Joural of Agricultural and Food Chemistry, 59, 10860-10868.

Melgar, B., Pereira, E., Oliveira, M. B. P. P., Garcia-Castello, E. M., Rodriguez-Lopez, A. D., Sokovic, M., ... Ferreira, I. C. F. R. (2017). Extensive profiling of three varieties of Opuntia spp fruit for innovative food ingredients. Food Research International, 101, 259-265.

Milivojevic, J., Maksimovic, V., Nikolic, M., Bogdanovic, J., Maletic, R., \& Milatovic, D. (2011). Chemical and antioxidant properties of cultivated and wild fragaria and rubus berries. Journal of Food Quality, 34, 1-9.

Morales, P., Ferreira, I. C. F. R., Carvalho, A. M., Fernández-Ruiz, V., Cortes Sánchez Mata, M., Cámara, M., ... Tardío, J. (2013). Wild edible fruits as a potential source of phytochemicals with capacity to inhibit lipid peroxidation. European Journal of Lipid Science and Technology, 115, 176-185.

Mingo, E., Silván, J. M., \& Martinez-Rodriguez, A. J. (2016). Selective antibacterial effect on Campylobacter of a winemaking waste extract (WWE) as a source of active phenolic compounds. Food Science and Technology, 68, 418-424.

Mori, T. A. (2018). Reprint of: Marine OMEGA-3 fatty acids in the prevention of 
cardiovascular disease. Fitoterapia, 126, 8-15.

Moscato, E. M., \& Machin, J. E. (2018). Mother natural: Motivations and associations for consuming natural foods. Appetite, 121, 18-28.

Moubarac, J. C., Batal, M., Louzada, M. L., Martinez Steele, E., \& Monteiro, C. A. (2017). Consumption of ultra-processed foods predicts diet quality in Canada. Appetite, 108, 512-520.

Nadeem, N., Woodside, J. V., Kelly, S., Allister, R., Young, I. S., \& McEneny, J. (2012). The two faces of $\alpha$ - and $\gamma$-tocopherols: An in vitro and ex vivo investigation into VLDL, LDL and HDL oxidation. Journal of Nutritional Biochemistry, 23, 845-851.

Ospina-E, J. C., Sierra, C. A., Ochoa, O., \& Pérez-Álvarez, J. A. (2012). Substitution of saturated fat in processed meat products: A Review. Critical Reviews in Food Science and Nutrition, 52, 113-122.

Oszmiański, J., Nowicka, P., Teleszko, M., Wojdyło, A., Cebulak, T., \& Oklejewicz, K. (2015). Analysis of phenolic compounds and antioxidant activity in wild blackberry fruits. International Journal of Molecular Sciences, 16, 14540-14553.

Panizzi, L., Caponi, C., Catalano, S., Cioni, P. L., \& Morelli, I. (2002). In vitro antimicrobial activity of extracts and isolated constituents of Rubus ulmifolius. Journal of Ethnopharmacology, 79, 165-168.

Papetti, A., Mascherpa, D., Carazzone, C., Stauder, M., Spratt, D. A., Wilson, M., .. Gazzani, G. (2013). Identification of organic acids in cichorium intybus inhibiting virulence-related properties of oral pathogenic bacteria. Food Chemistry, 138, 1706-1712.

Pellegrini, M., Lucas-Gonzales, R., Ricci, A., Fontecha, J., Fernández-López, J., PérezÁlvarez, J. A., \& Viuda-Martos, M. (2018). Chemical, fatty acid, polyphenolic profile, techno-functional and antioxidant properties of flours obtained from quinoa (Chenopodium quinoa Willd) seeds. Industrial Crops and Products, 111, 38-46.

Pereira, E., Barros, L., Martins, A., \& Ferreira, I. C. F. R. (2012). Towards chemical and nutritional inventory of Portuguese wild edible mushrooms in different habitats. Food Chemistry, 130, 394-403.

Pinela, J., Carvalho, A. M., \& Ferreira, I. C. F. R. (2017). Wild edible plants: Nutritional and toxicological characteristics, retrieval strategies and importance for today's society. Food and Chemical Toxicology, 110, 165-188.

Reidel, R., Melai, B., Cioni, P., Flamini, G., \& Pistelli, L. (2016). Aroma profile of Rubus ulmifolius flowers and fruits during different ontogenetic phases. Chemistry and Biodiversity, 13, 1776-1784.

Rincón-Cervera, M.Á., González-Barriga, V., Valenzuela, R., López-Arana, S., Romero, J., \& Valenzuela, A. (2019). Profile and distribution of fatty acids in edible parts of commonly consumed marine fishes in Chile. Food Chemistry, 274, 123-129.

Rodrigues, S., Calhelha, R. C., Barreira, J. C. M., Dueñas, M., Carvalho, A. M., Abreu, R. M. V., ... Ferreira, I. C. F. R. (2012). Crataegus monogyna buds and fruits phenolic extracts: Growth inhibitory activity on human tumor cell lines and chemical characterization by HPLC-DAD-ESI/MS. Food Research International, 49, 516-523.

Rodríguez-Roque, M. J., de Ancos, B., Sánchez-Moreno, C., Cano, M. P., Elez-Martínez, P. \& Martín-Belloso, O. (2015). Impact of food matrix and processing on the in vitro bioaccessibility of vitamin C, phenolic compounds, and hydrophilic antioxidant activity from fruit juice-based beverages. Journal of Functional Foods, 14, 33-43.

Roriz, C. L., Barros, L., Prieto, M. A., Morales, P., \& Ferreira, I. C. F. R. (2017). Floral parts of Gomphrena globosa L. as a novel alternative source of betacyanins: Optimization of the extraction using response surface methodology. Food Chemistry, 229, 223-234.

Ruiz-Rodríguez, B. M., Sánchez-Moreno, C., De Ancos, B., Sánchez-Mata, C., de, M. Fernández-Ruiz, V., ... Tardío, J. (2014). Wild Arbutus unedo L. and Rubus ulmifolius Schott fruits are underutilized sources of valuable bioactive compounds with antioxidant capacity. Fruits, 69, 435-448.

Sun, F., Dai, Y., \& Yu, X. (2017). Air pollution, food production and food security: A review from the perspective of food system. Journal of Integrative Agriculture, 16, 2945-2962.

Tallima, H., \& El Ridi, R. (2018). Arachidonic acid: Physiological roles and potential health benefits - A review. Journal of Advanced Research, 11, 33-41.

Tavares, L. R., Figueira, I., Macedo, D., McDougall, G. J., Leitao, M. C., Vieira, H. L. A., ... Santos, C. N. (2012). Neuroprotective effect of blackberry (Rubus sp.) polyphenols is potentiated after simulated gastronintestinal digestion. Food Chemistry, 131 1443-1452.

Uhler, B., \& Yang, Z. (2018). Rebaudioside a and other unreported steviol glycoside isomers found in the sweet tea (Rubus suavissimis) leaf. Phytochemistry Letters, 28, 93-97.

Van de Velde, F., Pirovani, M. E., \& Drago, S. R. (2018). Bioaccessibility analysis of anthocyanins and ellagitannins from blackberry at simulated gastrointestinal and colonic levels. Journal of Food Composition and Analysis, 72, 22-31.

Yang, J. Y., Pak, J.-H., \& Kim, S.-C. (2018). The complete plastome sequence of Rubus takesimensis endemic to Ulleung Island, Korea: Insights into molecular evolution of anagenetically derived species in Rubus (Rosaceae). Gene, 668, 221-228.

Zhang, N., Ju, Z., \& Zuo, T. (2018). Time for food: The impact of diet on gut microbiota and human health. Nutrition, 51-52, 80-85. 